\title{
O papel do professor no contexto educacional sob o ponto de vista dos alunos
}

\author{
Motivar a colaboração, a troca constante de informações e a \\ comunicação, mesmo que parcial, favorece a disseminação dos \\ achados individuais do corpo docente.
}

\author{
Denise Pontes Raldi*, Cláudia Fabrício Malheiros*, Íris Maria Fróis**, José Luiz \\ Lage-Marques***
* Professoras da Disciplina de Endodontia da Faculdade de Odontologia da Universidade Ibirapuera e da Faculdade de Odontologia da Universidade Vale do Paraíba.
** Professora Titular da Disciplina de Endodontia da Faculdade de Odontologia da Universidade Vale do Paraíba. Ibirapuera e Coordenador do Curso de Endodontia da Faculdade de Odontologia da Universidade de São Paulo. \\ *** Professor Titular da Disciplina de Endodontia da Universidade
}

\section{RESUMO}

Este estudo teve como objetivo avaliar a opinião dos alunos de quatro Faculdades de Odontologia do Estado de São Paulo, duas instituições particulares e duas estaduais, a respeito do papel do professor no processo de ensino-aprendizagem. Foram distribuídos 180 questionários, contendo quase que na totalidade questões fechadas, dos quais $50 \%$ foi respondido por alunos das faculdades estaduais e o restante por alunos das faculdades particulares. Foram avaliados os seguintes quesitos: qualidades necessárias de um professor competente, material didático e metodologia de ensino adotados, tempo de aula e atitudes dos professores. A opinião do corpo discente revelou que os professores têm um papel fundamental no processo de ensino-aprendizagem, sendo considerados competentes quando têm conhecimento, didática e vivência clínica. A análise estatística mostrou não haver diferença significante em relação à opinião dos alunos nas populações testadas das instituições particulares e públicas. Os resultados permitiram concluir que as atitudes do professor com os alunos, bem como o tipo de material didático adotado e o tempo despendido nas aulas teóricas podem tanto favorecer quanto prejudicar a aprendizagem.

\section{DESCRITORES}

Docentes. Educação em Odontologia. Alunos. Aprendizagem.

G rande ênfase tem sido dada às questões que cercam o processo de ensino-aprendizagem em decorrência das constantes mudanças ocorridas na nossa sociedade e, conseqüentemente, na área do ensino superior, o que certamente reflete nos cursos de graduação e pós-graduação de Odontologia.

Inúmeras estratégias de ensino têm sido propostas objetivando, dessa forma, o aprimoramento da educação do aluno universitário em amplo sentido, ou seja, o desenvolvimento intelectual, a formação de sentimentos, qualidades e valores (SANTOS, 2001).

Sabe-se, entretanto, que os indivíduos diferem entre si, razão pela qual os alunos não aprendem no mesmo ritmo, divergindo, segundo MATTOS (apud TURRA, 1990),

\footnotetext{
"quanto ao nível de maturação, capacidade, preparo escolar, bem como quanto a atitudes e ideais, interesses, preferências e padrões habituais de conduta e de reação".
} 
Quadro 1 - Modelo da entrevista realizada com 15 (quinze) alunos das Faculdades de Odontologia da USP, UNESP, UNIB e UNIVAP.

\begin{tabular}{|l} 
Aluno: \\
Faculdade:
\end{tabular}

1. Cite 6 (seis) qualidades de um bom professor.

2. O tipo de material didático e a metodologia utilizada influenciam na sua aprendizagem? Quais são os mais eficientes?

3. Algum professor (ou disciplina) utilizou uma metodologia de ensino interessante e inovadora em sala de aula e que favoreceu sua aprendizagem? Qual?

4. A duração das aulas ou atividades teóricas é um fator que interfere na aprendizagem? Aulas muito longas não são produtivas? Quanto tempo você consegue prestar atenção?

5. O professor pode ser responsável pelo desinteresse do aluno por uma disciplina? Que atitudes do professor podem prejudicar sua aprendizagem? (Teórica e prática).

6. O professor pode ser responsável pelo interesse do aluno por uma disciplina? Que atitudes do professor podem favorecer sua aprendizagem? (Teórica e prática).

7. Na sua opinião quem é o maior responsável pela sua aprendizagem? O aluno ou o professor (de preferência defina em \%).

Estudos têm avaliado a opinião dos estudantes a respeito do que ocorre em sala de aula. Entre eles, destacam-se os de MASETTO $(1992,1996)$ e de LUQUE, PEÇANHA (1998), que a partir de suas pesquisas conseguiram identificar um conjunto de condições que, segundo a opinião do alunado, são facilitadoras de seu processo de aprendizagem.

Este estudo teve como objetivo verificar, por meio de um questionário, a opinião dos alunos de quatro Faculdades de Odontologia do Estado de São Paulo a respeito do papel do professor no processo de ensino-aprendizagem.

\section{MATERIAL E MÉTODOS}

Este estudo foi realizado com 180 (cento e oitenta) alunos de $3^{\circ}, 4^{\circ}$ e $5^{\circ}$ anos de quatro Faculdades de Odontologia do Estado de São Paulo: duas particulares (Faculdade de Odontologia da Universidade
Ibirapuera* e Faculdade de Odontologia da Universidade Vale do Paraíba**) e duas instituições públicas (Faculdade de Odontologia da Universidade de São Paulo ${ }^{\dagger}$ e Faculdade de Odontologia de São José dos Campos - $\mathrm{UNESP}^{\dagger \dagger}$ ).

Numa primeira etapa, foi realizada uma entrevista com 15 (quinze) alunos com o objetivo de elaborar um questionário específico e direcionado que permitisse, com maior exatidão, avaliar a opinião dos alunos em relação ao papel do professor no processo de ensino-aprendizagem (Quadro 1).

Na segunda etapa, o questionário, (Quadro 2), foi preenchido por 180 (cento e oitenta) alunos: 90 alunos das faculdades particulares (30 alunos da UNIB e 60 alunos da UNIVAP) e 90 alunos das faculdades particulares (30 alunos da USP e 60 alunos da UNESP). Foram avaliados os seguintes quesitos: atributos de um professor competente, tipo de material

\footnotetext{
*Faculdade de Odontologia da Universidade Ibirapuera (UNIB) - São Paulo - SP.

**Faculdade de Odontologia da Universidade Vale do Paraíba (UNIVAP) - São José dos Campos - SP.

†Faculdade de Odontologia da Universidade de São Paulo (USP) - SP.

††Faculdade de Odontologia de São José dos Campos - UNESP - São José dos Campos - SP.
} 
Quadro 2 - Modelo do questionário distribuído para 180 (cento e oitenta) alunos das Faculdades de Odontologia da USP, UNESP, UNIB E UNIVAP.

\begin{tabular}{|l|l|}
\hline $\begin{array}{l}\text { Aluno: } \\
\text { Faculdade: } \\
\text { Assinale as respostas de acordo com os seguintes itens: }\end{array}$ \\
\hline \multicolumn{1}{c|}{ O PAPEL DO PROFESSOR NA APRENDIZAGEM DO ALUNO } \\
\hline $\begin{array}{l}\text { 1. Selecione os } 3 \text { (três) principais requisitos de um professor competente: } \\
\text { ( ) ter conhecimento ( ) ser acessível ( ) ser amigo ( ) ter didática ( ) ter segurança }\end{array}$ \\
( ) ter titulação (mestrado, doutorado) ( ) ter vivência ou experiência clínica ( ) ser objetivo
\end{tabular}

2. O tipo de material didático influencia a sua Selecione os dois mais eficientes para sua aprendizagem: aprendiagem?

( ) nunca

( ) raramente

( ) quadro negro e giz ( ) datashow ( ) slides/projetor

( ) às vezes

( ) demonstrações práticas: workshop ( ) seminários ( )

( ) sempre

3. Algum professor (ou disciplina) utilizou uma metodologia de ensino interessante e inovadora em sala de aula e que favoreceu sua aprendizagem?

( ) $\operatorname{sim}($ ) não

4. A duração das aulas ou atividades teóricas é um fator que interfere na aprendizagem (ex.: aulas muito longas podem interferir na sua aprendizagem)?

( ) nunca ( ) raramente

( ) às vezes ( ) sempre outros (identifique):

Qual (is)?

5. O professor pode ser responsável pelo Selecione duas atitudes do professor que podem desinteresse do aluno por uma disciplina?

( ) $\operatorname{sim}$

( ) não

Selecione o tempo máximo que você consegue ficar concentrado ou prestar atenção numa aula ou atividade teórica:

( ) meia hora ( ) 1 hora

( ) 1 hora e meia ( ) 2 horas ou mais

( ) o tempo não interfere se o assunto for interessante prejudicar sua aprendizagem:

( ) menosprezar o aluno ( ) ser muito exigente

( ) não ser justo ao avaliar o aluno (nota)

( ) demonstrar falta de interesse pela aprendizagem dos alunos

( ) ser repetitivo ( ) outros (identifique):

6. O professor pode ser responsável pelo interesse do aluno por uma disciplina?

( ) $\operatorname{sim}$

( ) não

Selecione duas atitudes do professor que podem facilitar sua aprendizagem:

( ) estimular ou incentivar o aluno

( ) ser inovador nas aulas ( ) relacionar a teoria com a prática ( ) fazer o aluno pensar ( ) outros (identifique):

7. Na sua opinião quem é o responsável pela sua aprendizagem?

( ) aluno $100 \%$ ( ) aluno $50 \%$ e professor $50 \%$ ( ) professor (mais de $70 \%$ )

( ) professor $100 \%$ ( ) aluno (mais de $70 \%$ ) 
Tabela 1- Opinião dos alunos (\%) em relação ao papel dos professores no processo de ensino-aprendizagem. Principais requisitos de um professor competente.

\begin{tabular}{|c|c|c|c|c|c|c|c|}
\hline & $\begin{array}{c}\text { Total } \\
\text { alunos }\end{array}$ & UNIB & UNIVAP & $\begin{array}{c}\text { Média } \\
\text { particulares }\end{array}$ & $\begin{array}{c}\text { Média } \\
\text { públicas }\end{array}$ & UNESP & USP \\
\hline \multicolumn{8}{|c|}{ Principais requisitos de um professor competente } \\
\hline Ter conhecimento & $87,7^{\mathrm{a}}$ & $77,8^{\mathrm{a}}$ & $83,1^{\mathrm{a}}$ & $80,4^{a}$ & $80,1^{b}$ & $74,1^{\mathrm{b}}$ & $86,2^{b}$ \\
\hline Ter didática & $77,3^{\mathrm{b}}$ & $66,7^{\mathrm{b}}$ & $45,8^{c}$ & $56,2^{b}$ & $91,7^{a}$ & $83,3^{a}$ & $100,0^{\mathrm{a}}$ \\
\hline Ter vivência clínica & $54,5^{c}$ & $48,1^{c}$ & $57,6^{b}$ & $52,9^{c}$ & $41,4^{c}$ & $51,9^{c}$ & 31,0 \\
\hline Ser acessível & 43,5 & 44,4 & 40,7 & 42,6 & 39,1 & 33,3 & $44,8^{c}$ \\
\hline Ter segurança & 22,1 & 18,5 & 23,7 & 21,1 & 17,9 & 18,5 & 17,2 \\
\hline Ser objetivo & 17,5 & 18,5 & 8,5 & 13,5 & 22,1 & 16,7 & 27,6 \\
\hline Ser amigo & 14,9 & 22,2 & 20,3 & 21,3 & 5,4 & 7,4 & 3,4 \\
\hline Ter titulação & 5,8 & 3,7 & 10,2 & 6,9 & 1,9 & 3,7 & 0,0 \\
\hline Ser rigoroso & 3,2 & 0,0 & 6,8 & 3,4 & 1,7 & 0,0 & 3,4 \\
\hline Ser bonzinho & 0,0 & 0,0 & 0,0 & 0,0 & 0,0 & 0,0 & 0,0 \\
\hline
\end{tabular}

$\mathrm{a}_{1}$ o mais votado; ${ }^{\mathrm{b}} 2 \mathrm{o}$ mais votado; ${ }^{\mathrm{c}} 3$ o mais votado.

didático e metodologia de ensino adotados, duração da aula e atitude dos professores.

Após a verificação e interpretação dos resultados foi realizada a análise estatística dos dados.

\section{RESULTADOS}

Os resultados obtidos estão expressos no Gráfico 1 e nas Tabelas 1 a 6, e representam a opinião dos alunos em relação ao papel do professor na sua aprendizagem. Esses resultados foram submetidos à análise estatística pelo teste de concordância - W de Kendall. Utilizou-se o programa estatístico GMC ${ }^{\dagger+\dagger}$, e constatou-se que não houve diferença estatisticamente significante entre as duas populações testadas: alunos de escolas particulares e alunos de instituições públicas.

\section{Discussão}

Somente conhecendo os interesses e as necessidades de seus alunos é que os professores podem criar situações de ensino que atendam às características de aprendizagem dos estudantes, bem como que garantam a eficácia do seu papel de educador (SANTOS, 2001).

MASSETTO (1992) verificou, em seu estudo com alunos do $3^{\circ}$ grau, que as características do professor são dos fatores mais importantes a serem considera-
Gráfico 1 - Opinião dos alunos (\%) em relação à responsabilidade da aprendizagem.

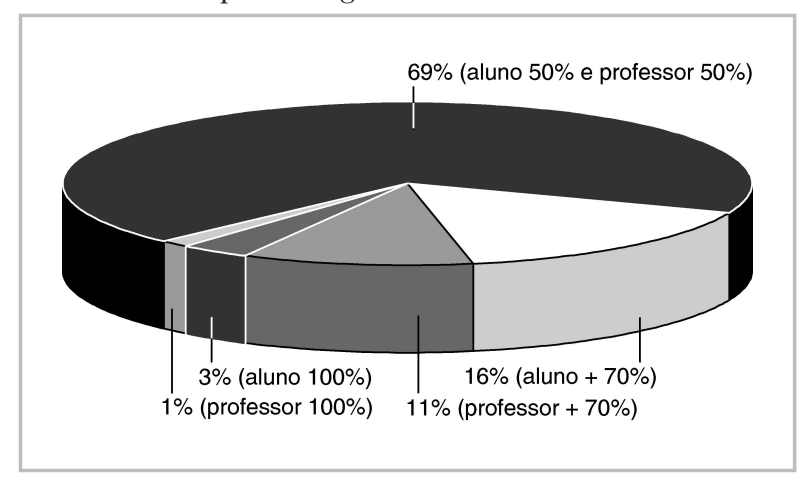

dos como facilitador de aprendizagem, na medida em que motiva e desperta o interesse de seus alunos. Foram indicadas como características importantes: coerência entre o discurso e a ação do professor em aula e fora dela; competência específica em sua área de conhecimento e em didática; clareza e objetividade na transmissão de informações; incentivo à participação e capacidade de coordenação das atividades; segurança; abertura à crítica e às propostas dos alunos; capacidade de diálogo; preocupação com os alunos e seus interesses; relacionamento pessoal e amigo; paixão pela docência.

Já neste estudo, as características mais importantes de um bom professor apontadas pelos alunos fo††Programa estatístico GMC - versão 2002 (Professor Geraldo Maia Campos, da Faculdade de Odontologia de Ribeirão Preto, USP,
Ribeirão Preto). 
Tabela 2 - Opinião dos alunos (\%) em relação ao papel dos professores no processo de ensino-aprendizagem. Influência do material didático na aprendizagem do aluno.

\begin{tabular}{|c|c|c|c|c|c|c|c|}
\hline & $\begin{array}{c}\text { Total } \\
\text { alunos }\end{array}$ & UNIB & UNIVAP & $\begin{array}{c}\text { Média } \\
\text { particulares }\end{array}$ & $\begin{array}{c}\text { Média } \\
\text { públicas }\end{array}$ & UNESP & USP \\
\hline \multicolumn{8}{|c|}{ Influência do material didático na aprendizagem do aluno } \\
\hline Sempre & $69,5^{\mathrm{a}}$ & $55,6^{a}$ & $76,3^{a}$ & $65,9^{a}$ & $58,7^{a}$ & $51,9^{a}$ & $65,5^{a}$ \\
\hline Às vezes & $30,0^{b}$ & $40,7^{b}$ & $22,0^{b}$ & $31,4^{b}$ & $41,3^{\mathrm{b}}$ & $48,1^{b}$ & $34,5^{b}$ \\
\hline Raramente & 1,5 & 3,7 & 1,7 & 2,7 & 0,0 & 0,0 & 0,0 \\
\hline Nunca & 0,0 & 0,0 & 0,0 & 0,0 & 0,0 & 0,0 & 0,0 \\
\hline \multicolumn{8}{|c|}{ Meios eficientes } \\
\hline Demonstrações práticas - workshop & $76,6^{a}$ & $59,3^{b}$ & $78,0^{a}$ & $68,6^{a}$ & $65,4^{a}$ & $72,2^{a}$ & $58,6^{a}$ \\
\hline Multimídia & $64,3^{b}$ & $66,7^{a}$ & $50,8^{b}$ & $58,8^{b}$ & $60,8^{b}$ & $63,0^{b}$ & $58,6^{a}$ \\
\hline Quadro negro e giz & $23,4^{c}$ & $29,6^{c}$ & 15,3 & 22,4 & $26,4^{c}$ & 14,8 & $37,9^{b}$ \\
\hline Slide/projetor & 22,1 & 22,2 & $32,2^{c}$ & $27,2^{c}$ & 8,3 & $16,7^{c}$ & 0,0 \\
\hline Seminários & 20,1 & 22,2 & 15,3 & 18,7 & 22,0 & 13,0 & $31,0^{c}$ \\
\hline Outros & 0,6 & 0,0 & 0,0 & 0,0 & 0,9 & 1,9 & 0,0 \\
\hline
\end{tabular}

Tabela 3 - Opinião dos alunos (\%) em relação ao papel dos professores no processo de ensino-aprendizagem. Utilização de metodologia interessante.

\begin{tabular}{|c|c|c|c|c|c|c|c|}
\hline & $\begin{array}{c}\text { Total } \\
\text { alunos }\end{array}$ & UNIB & UNIVAP & $\begin{array}{c}\text { Média } \\
\text { particulares }\end{array}$ & $\begin{array}{c}\text { Média } \\
\text { públicas }\end{array}$ & UNESP & USP \\
\hline \multicolumn{8}{|c|}{ Utilização de metodologia interessante } \\
\hline Não & $60,4^{a}$ & $40,7^{a}$ & $45,8^{a}$ & $43,3^{a}$ & $66,1^{\mathrm{a}}$ & $66,7^{a}$ & $65,5^{a}$ \\
\hline Sim & 39,6 & 59,3 & 54,2 & 56,7 & 29,5 & 31,5 & 27,6 \\
\hline \multicolumn{8}{|c|}{ Quais? } \\
\hline Seminários & 4,5 & 11,1 & 1,7 & 6,4 & 4,4 & 1,9 & 6,9 \\
\hline
\end{tabular}

ram: conhecimento na disciplina $(87 \%)$, a didática (77\%), a experiência clínica $(54 \%)$ e a acessibilidade ou facilidade de relacionamento com os alunos $(43 \%)$.

Esses resultados coincidem com o que é preconizado pela área educacional e pedagógica atual. Para SANTOS (2001) a prática correta do professor de ensino superior deve estar assentada sobre três pontos principais: o conteúdo da área na qual é um especialista, sua visão de educação e as habilidades e os conhecimentos que lhe permitem uma efetiva ação pedagógica em sala de aula.

Vale ressaltar que, há algum tempo, os professores de Odontologia caracterizavam-se como especialistas em seu campo de conhecimento (esse era um critério para sua seleção e contratação) e muitos de- les não tinham conhecimento na área educacional ou pedagógica.

Atualmente, tem-se verificado que a titulação do professor é o critério mais exigido pelas instituições. Entretanto, neste estudo apenas 5,8\% dos alunos consideraram a titulação como um quesito importante.

Um segundo fator analisado foi a influência do material didático, visto que as estratégias adotadas em sala de aula são sem dúvida elementos facilitadores da aprendizagem.

Neste estudo, na opinião dos alunos, a metodologia empregada tem um papel importante na aprendizagem, sendo que as demonstrações práticas ou workshops são as mais eficientes. Esses resultados estão de acordo com estudos de MARULLI (1996), que 
Tabela 4 - Opinião dos alunos (\%) em relação ao papel dos professores no processo de ensino-aprendizagem. A duração das aulas ou atividades teóricas interfere na aprendizagem?

\begin{tabular}{|c|c|c|c|c|c|c|c|}
\hline & $\begin{array}{l}\text { Total } \\
\text { alunos }\end{array}$ & UNIB & UNIVAP & $\begin{array}{c}\text { Média } \\
\text { particulares }\end{array}$ & $\begin{array}{l}\text { Média } \\
\text { públicas }\end{array}$ & UNESP & USP \\
\hline \multicolumn{8}{|c|}{ A duração das aulas ou atividades teóricas interfere na aprendizagem? } \\
\hline Sempre & $55,2^{a}$ & $70,4^{a}$ & $32,2^{\mathrm{b}}$ & $51,3^{a}$ & $58,7^{a}$ & $51,9^{a}$ & $65,5^{a}$ \\
\hline Às vezes & $53,2^{b}$ & $25,9^{b}$ & $66,1^{\mathrm{a}}$ & $46,0^{b}$ & $41,3^{b}$ & $48,1^{\mathrm{b}}$ & $34,5^{b}$ \\
\hline Raramente & 1,3 & 3,7 & 1,7 & 2,7 & 0,0 & 0,0 & 0,0 \\
\hline Nunca & 0,0 & 0,0 & 0,0 & 0,0 & 0,0 & 0,0 & 0,0 \\
\hline \multicolumn{8}{|c|}{ Tempo máximo que você consegue ficar concentrado } \\
\hline 1 hora e meia & $63,6^{a}$ & $59,3^{a}$ & $50,8^{a}$ & $55,1^{a}$ & $62,5^{a}$ & $63,0^{a}$ & $62,1^{a}$ \\
\hline Não interfere - assunto importante & $21,4^{b}$ & $18,5^{c}$ & $27,1^{b}$ & $22,8^{b}$ & $12,7^{c}$ & $18,5^{b}$ & $6,9^{c}$ \\
\hline 1 hora & $18,2^{c}$ & $22,2^{\mathrm{b}}$ & $10,2^{c}$ & $16,2^{\mathrm{c}}$ & $20,4^{b}$ & $16,7^{c}$ & $24,1^{b}$ \\
\hline 2 horas e meia & 5,2 & 0,0 & $10,2^{c}$ & 5,1 & 2,7 & 1,9 & 3,4 \\
\hline Meia hora & 1,3 & 0,0 & 1,7 & 0,8 & 1,7 & 0,0 & 3,4 \\
\hline
\end{tabular}

realizou, por meio de questionários, um estudo com alunos do curso de Medicina Veterinária da Universidade de Marília e verificou que, para $82,0 \%$ deles, as aulas práticas são as que mais facilitam a aprendizagem.

LODER (2002) verificou, em seu estudo com alunos de engenharia da Universidade Federal do Rio Grande do Sul, que as atividades em laboratório ajudam na aprendizagem dos alunos. $\mathrm{O}$ autor concluiu que as atividades práticas possibilitam não só a ação do aluno, mas também a maior interação professor-aluno.

A aula expositiva ainda é a estratégia de ensino mais empregada nas escolas superiores e, para alguns professores é tida com a única estratégia possível. Neste estudo, foi possível observar que os alunos preferem aulas teóricas ministradas com o auxílio de "datashow", provavelmente por ser mais dinâmica. Apesar de ser criticada por alguns educadores, na opinião de MASETTO, ABREU (1997) não há nada de errado nesse tipo de estratégia, desde que se leve em consideração alguns fatores como habilidade do professor, planejamento da aula e forma de "transmitir" o conhecimento.

Cada docente deve encontrar a fórmula mais adequada de associar a tecnologia ao método de ensino-aprendizado. É extremamente importante que aprenda a dominar as mais variadas formas de comunicação. Não se trata de dar receitas, porque as situações são por demais diversificadas.
O tempo de duração da aula também é um dos fatores que deve ser considerado, devendo o professor, ao preparar sua aula expositiva, levar em consideração que há um limite de tempo (MAsseTto, ABREU, 1997). Neste estudo, para a maioria dos alunos $(96 \%)$, de fato, o tempo de aula pode influenciar na aprendizagem, sendo uma hora e meia o tempo máximo que eles conseguem ficar atentos.

Um outro fator a ser considerado como fundamental na aprendizagem, é o relacionamento professor-aluno. Verificou-se neste estudo, que o professor, dependendo de suas atitudes, pode ser responsável tanto pelo interesse como pelo total desestímulo de seus alunos. Relacionar teoria com prática e o incentivo foram consideradas duas atitudes positivas, enquanto o menosprezo ao aluno e a injustiça em relação a notas, por exemplo, foram consideradas as duas atitudes negativas.

Esses resultados estão de acordo com a literatura. Uma pesquisa da revista Time apud BORDENAVE, PEREIRA (1998) revelou que os melhores professores dos Estados Unidos não eram precisamente os que usavam as técnicas de ensino mais refinadas, mas sim os que, estimulados por seu entusiasmo para contagiar os seus alunos com amor à sua disciplina, encontravam maneiras próprias de comunicar e ensinar.

GODOY et al. (2002) analisaram as preferências dos alunos do curso superior de Administração de Empresas sobre vários aspectos que interferem no seu processo de aprendizagem. Foi constatada a pre- 
O papel do professor no contexto educacional sob o ponto de vista dos alunos • Raldi DP et al.

Tabela 5 - Opinião dos alunos (\%) em relação ao papel dos professores no processo de ensino-aprendizagem. O professor pode ser responsável pelo desinteresse do aluno por uma disciplina?

\begin{tabular}{|c|c|c|c|c|c|c|c|}
\hline & $\begin{array}{c}\text { Total } \\
\text { alunos }\end{array}$ & UNIB & UNIVAP & $\begin{array}{c}\text { Média } \\
\text { particulares }\end{array}$ & $\begin{array}{c}\text { Média } \\
\text { públicas }\end{array}$ & UNESP & USP \\
\hline \multicolumn{8}{|c|}{ O professor pode ser responsável pelo desinteresse do aluno por uma disciplina? } \\
\hline Sim & $96,1^{a}$ & $96,3^{a}$ & $98,3^{a}$ & $97,3^{a}$ & $95,5^{a}$ & $94,4^{a}$ & $96,6^{a}$ \\
\hline Não & 3,9 & 3,7 & 1,7 & 2,7 & 4,5 & 5,6 & 3,4 \\
\hline \multicolumn{8}{|c|}{ Atitudes do professor que podem prejudicar sua aprendizagem } \\
\hline Menosprezar o aluno & $76,6^{a}$ & $92,6^{a}$ & $76,3^{a}$ & $84,4^{a}$ & $56,4^{a}$ & $61,1^{a}$ & $51,7^{c}$ \\
\hline Não ser justo ao avaliar o aluno & $57,1^{\mathrm{b}}$ & $33,3^{c}$ & $50,8^{b}$ & $42,1^{\mathrm{c}}$ & $58,1^{\mathrm{b}}$ & $61,1^{\mathrm{a}}$ & $55,2^{b}$ \\
\hline $\begin{array}{l}\text { Falta de interesse pelo aprendizado } \\
\text { do aluno }\end{array}$ & $55,8^{c}$ & $59,3^{b}$ & $47,5^{c}$ & $53,4^{b}$ & $53,3^{c}$ & $44,4^{b}$ & $62,1^{\mathrm{a}}$ \\
\hline Ser repetitivo & 9,7 & 3,7 & 5,1 & 4,4 & 14,2 & 11,1 & 17,2 \\
\hline Ser muito exigente & 3,9 & 0,0 & 5,1 & 2,5 & 4,4 & 1,9 & 6,9 \\
\hline
\end{tabular}

ferência por professores que apresentam, como características pessoais, alto nível de entusiasmo pelo trabalho docente (96,3\% de concordância), usam de humor durante as aulas $(86,9 \%$ de concordância) e elogiam e encorajam os alunos $(89,4 \%$ de concordância).

LUQUE, PEÇANHA (1998) realizaram um estudo como o objetivo de analisar os processos em que a relação autoritária do professor com o aluno representa uma barreira que impede aquele último de desenvolver o seu potencial de criatividade e autonomia, sendo assim reprimido pelos diversos métodos utilizados pelos professores-controladores. Os autores concluíram que cabe aos futuros professores atuarem junto aos seus alunos de uma maneira auxiliar: sugerindo, estimulando, cooperando mas não decidindo, incutindo naqueles o espírito de equipe e a capacidade de troca com diferentes indivíduos.

Sem sombra de dúvida o professor tem um papel de fundamental importância no aprendizado dos alunos. O presente estudo observou que a maioria dos alunos $(80 \%)$ atribui aos professores grande responsabilidade pela sua aprendizagem. Esses resultados estão de acordo com os estudos de MARULLI (1996), segundo o qual verificou-se que, apesar de o processo de aprendizagem ser pessoal e depender da conduta do aluno, 46,0\% dos estudantes responderam enfatizando a figura do professor como responsável pela sua aprendizagem, contra 20,0\% que voltaram para si, enquanto alunos, a responsabilidade de aprender.

Julgou-se relevante avaliar, neste estudo, dois ti- pos de população - alunos de escolas particulares e alunos de escolas públicas -, para que os resultados pudessem realmente refletir, com maior exatidão, a opinião dos alunos de Odontologia. Os resultados mostraram que não houve diferença estatisticamente significante entre as populações testadas.

Diante do exposto, é possível afirmar que a educação no sentido amplo é um processo complexo e trabalhoso, por outro lado, muito gratificante para aqueles que a praticam. Salienta-se que as constatações observadas neste estudo devem estimular os professores a refletir sobre sua importância na aprendizagem dos alunos, procurando, assim, utilizar todos os recursos e meios para atingirem seus objetivos. É importante que cada docente busque o caminho para comunicar-se bem, ensinar bem, ajudar os alunos a que aprendam melhor.

A análise crítica do desenvolvimento de cada projeto de ensino-aprendizado muita vez traz a dúvida sobre realizar ou não qualquer mudança. Trata-se de um desafio muito mais relacionado com o conceitual do que com o prático. Nesta fase, o exercício democrático do diálogo exige destreza no emprego de habilidades administrativas que se desenvolvem, tanto dentro quanto fora da organização, buscando evidenciar a todos os envolvidos, o bom senso, convidando-os a participar de forma concreta e criativa para alcançar os objetivos.

Motivar a colaboração, a troca constante de informações, e a comunicação mesmo parcial, favorece a disseminação dos achados individuais do corpo docente. Sem dúvida é mais civilizado aprender pela 
Tabela 6 - Opinião dos alunos (\%) em relação ao papel dos professores no processo de ensino-aprendizagem. O professor pode ser responsável pelo interesse do aluno por uma disciplina?

\begin{tabular}{|c|c|c|c|c|c|c|c|}
\hline & $\begin{array}{l}\text { Total } \\
\text { alunos }\end{array}$ & UNIB & UNIVAP & $\begin{array}{c}\text { Média } \\
\text { particulares }\end{array}$ & $\begin{array}{l}\text { Média } \\
\text { públicas }\end{array}$ & UNESP & USP \\
\hline \multicolumn{8}{|c|}{ O professor pode ser responsável pelo interesse do aluno por uma disciplina? } \\
\hline Sim & $96,8^{a}$ & $100,0^{a}$ & $93,2^{\mathrm{a}}$ & $96,6^{a}$ & $99,1^{a}$ & $98,1^{\mathrm{a}}$ & $100,0^{\mathrm{a}}$ \\
\hline Não & 3,2 & 0,0 & 6,8 & 3,4 & 0,9 & 1,9 & 0,0 \\
\hline \multicolumn{8}{|c|}{ Atitudes do professor que podem facilitar sua aprendizagem } \\
\hline Relacionar teoria com prática & $83,1^{a}$ & $74,1^{\mathrm{a}}$ & $64,4^{b}$ & $69,2^{\mathrm{b}}$ & $85,6^{a}$ & $81,5^{a}$ & $89,7^{a}$ \\
\hline Estimular ou incentivar o aluno & $74,7^{\mathrm{b}}$ & $63,0^{b}$ & $78,0^{a}$ & $70,5^{a}$ & $62,5^{b}$ & $63,0^{\mathrm{b}}$ & $62,1^{\mathrm{b}}$ \\
\hline Fazer o aluno pensar & 31,2 & 18,5 & 20,3 & 19,4 & 35,9 & 40,7 & 31,0 \\
\hline Ser inovador nas aulas & 27,9 & 33,3 & 35,6 & 34,5 & 16,8 & 13,0 & 20,7 \\
\hline
\end{tabular}

$a_{10}$ mais votado; ${ }^{b}$ o mais votado.

colaboração, pela cooperação do que da competição. O professor estará atento e intimamente envolvido aos vários ritmos, e as experiências servirão de elo entre todos.

Por fim, vale ressaltar que o segredo do bom ensino é o entusiasmo pessoal do professor, que muitas vezes depende das condições propiciadas pelas próprias instituições de ensino, as quais, igualmente, devem estar cientes da importância do professor no processo de ensino-aprendizagem dos alunos do $3^{\underline{o}}$ grau.

\section{Conclusões}

$\mathrm{Na}$ opinião do corpo discente foi possível concluir que:

1. Os professores têm um papel fundamental no processo de ensino-aprendizagem, sendo considerados competentes quando têm conhecimento, didática e vivência clínica.

2. Suas atitudes com os alunos, bem como o tipo de material didático adotado e o tempo despendido nas aulas teóricas, podem tanto favorecer quanto prejudicar a aprendizagem.

3. As análises dos resultados não permitiram observar diferenças estatisticamente significantes, em relação à opinião dos alunos, nas duas populações testadas.

\section{ABSTRACT}

The role of the teacher in an educational context from the students' point of view

The aim of the present study was to ascertain the opinions of students from four universities on the role of the teacher in their learning. The students were selected from two private and two public universities in the state of São Paulo. The first part of the study consisted of an interview with 15 students (chosen randomly) to prepare a specific questionnaire to evaluate which factors are related to their learning. In the second part, the questionnaires were answered by 90 private university students and 90 public university students. Their opinions were: teachers have an important role in the teaching and learning process and their attributes, didactic tools chosen and time spent on a class can help or hinder the students' learning. No statistical differences were observed between the students' opinions of both private and public universities.

\section{DESCRIPTORS}

Faculty. Education, dental. Students. Learning.

\section{REFERÊNCIAS}

BORDENAVE, J. D.; PEREIRA, A. M. Estratégias de ensino-aprendizagem. 18. ed. Petrópolis : Editora Vozes, 1998. 312 p.

GODOY, A. S. et al. Preferências de ensino: estudo exploratório com alunos do curso superior de Administração de Empresas. Revista Administração OnLine, v. 2, 2002. Disponível em: http://www.fecap.br/adm_online/adol/artigo.htm.

LODER, L. L. Processos de ensino-aprendizagem em Cursos de Engenharia. In: VII International Conference on Engineering and Technology Education, 2002, Santos. Anais do Congresso em CD-ROM.

LUQUE, M. S.; PEÇANHA, U. F. Poder e aprendizagem: uma breve análise das relações entre aluno e professor. In: BELLO, J. L. P. Pedagogia em foco. Rio de Janeiro, 1998. Disponível em: http://www.pedagogiaemfoco.pro.br/filos04.htm. 
MARULLI, K. B. B. Fatores que interferem no processo ensino-aprendizagem, segundo a opinião de alunos do curso de Medicina Veterinária da Universidade de Marília - UNIMAR. Unimar Ciências, v. 5, n. 1, p. 68 -75, 1996.

MASETTO, M. T. Aulas vivas. 2. ed. São Paulo: MG Editora, 1996. $104 \mathrm{p}$.

MASETTO, M. T.; ABREU, M. C. O professor universitário em aula. 11. ed. São Paulo: M.G. Editora, 1997. 130 p.

MASETTO, M. T. Ensino-aprendizagem no $3^{\circ}$ grau. In: D'ANTOLA, A. (org.). A prática docente na universidade. São Paulo:
EPU, 1992. p. 19-26.

SANTOS, S. C. O processo de ensino-aprendizagem e a relação professor aluno: aplicação dos "sete princípios para a boa prática na educação de ensino superior”. Caderno de Pesquisas em Administração, v. 8, n. 1, p. 69-82, jan./mar. 2001.

TURRA, C. M. G. et al. Planejamento de ensino avaliação. Porto Alegre : Sagra, 1990.

Aceito para publicação em 11/2003

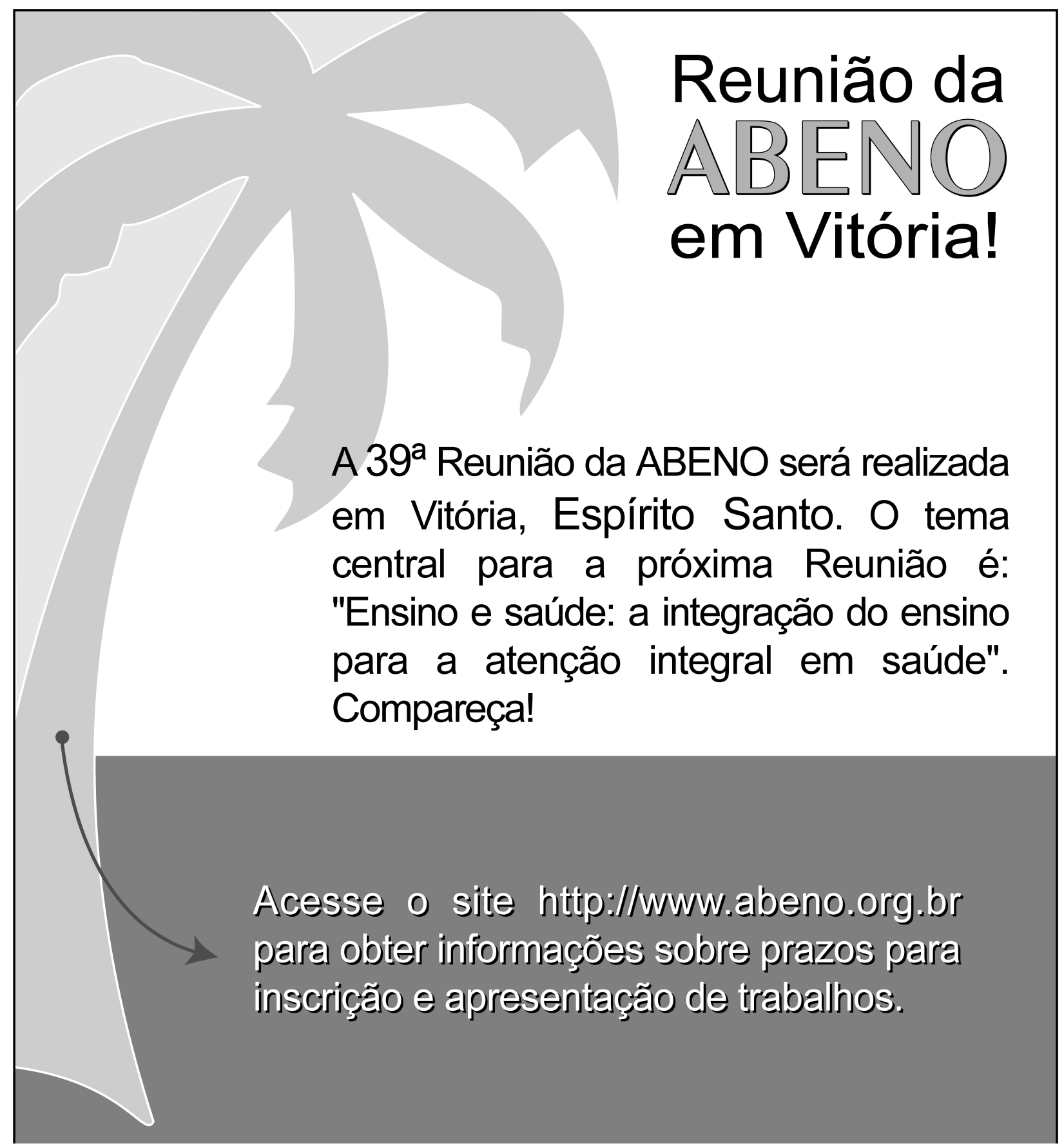

